\title{
Stabilizing Hybrid Electrochromic Devices through Pairing Electrochromic Polymers with Minimally Color-Changing lon- Storage Materials Having Closely Matched Electroactive \\ Voltage Windows
}

Xuefei Li, ${ }^{\dagger}$ Zhiyang Wang, ${ }^{\dagger}$ Ke Chen, ${ }^{\dagger}$ Dmitry Y. Zemlyanov,${ }^{\ddagger}$ Liyan You, ${ }^{\dagger}$ and Jianguo $\mathrm{Mei}^{*},+, *$

$\dagger$ Department of Chemistry, Purdue University, West Lafayette, Indiana 47907, United States

\$irck Nanotechnology Center, Purdue University, West Lafayette, Indiana 47907, United States 
a

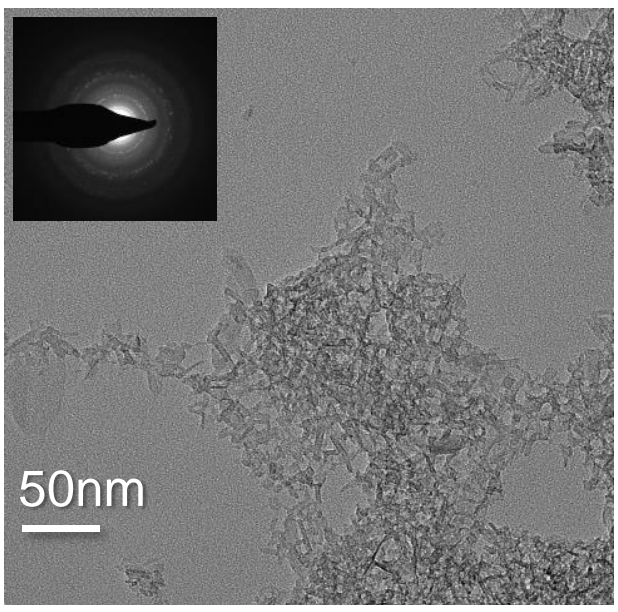

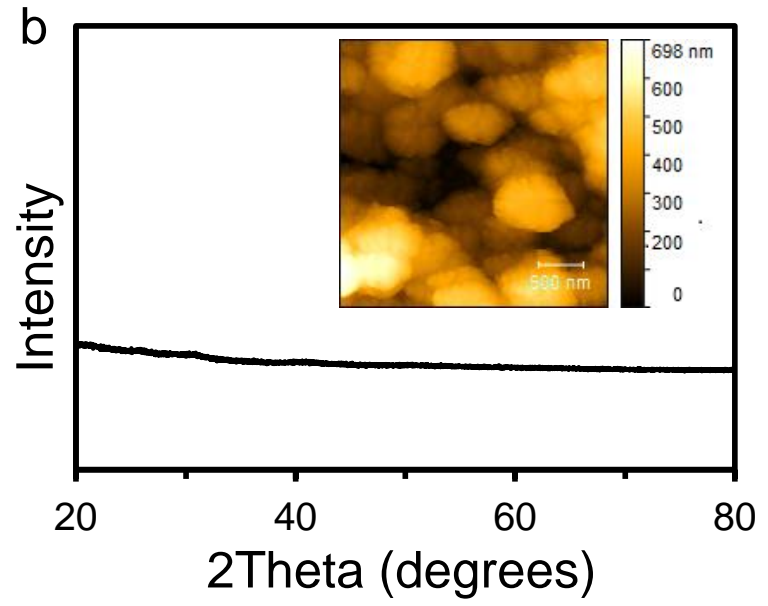

Figure S1. (a) TEM image of the $\mathrm{VO}_{\mathrm{x}}$ nanostructures, with the SAED pattern in the inset. (b) XRD and AFM (inset) data of the $\mathrm{VO}_{\mathrm{x}}$ thin films after low-temperature thermal annealing and UV-ozone processing.
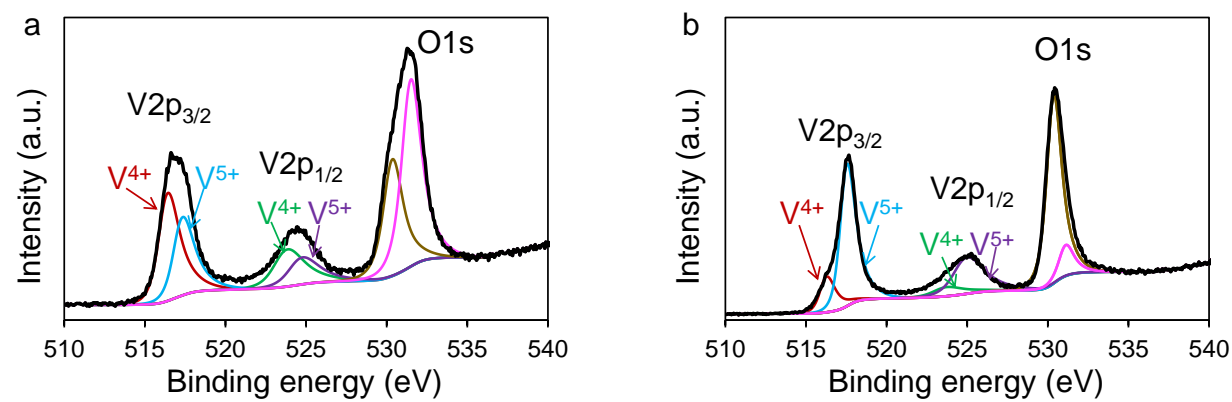

Figure S2. O 1s/V 2p XPS spectra of the $\mathrm{VO}_{x}$ thin film after (a) thermal annealing and (b) UV-ozone processing. After the UV-ozone processing, the $\mathrm{V}^{5+}$ to $\mathrm{V}^{4+}$ ratio increased from about 3:4 to 4:1.

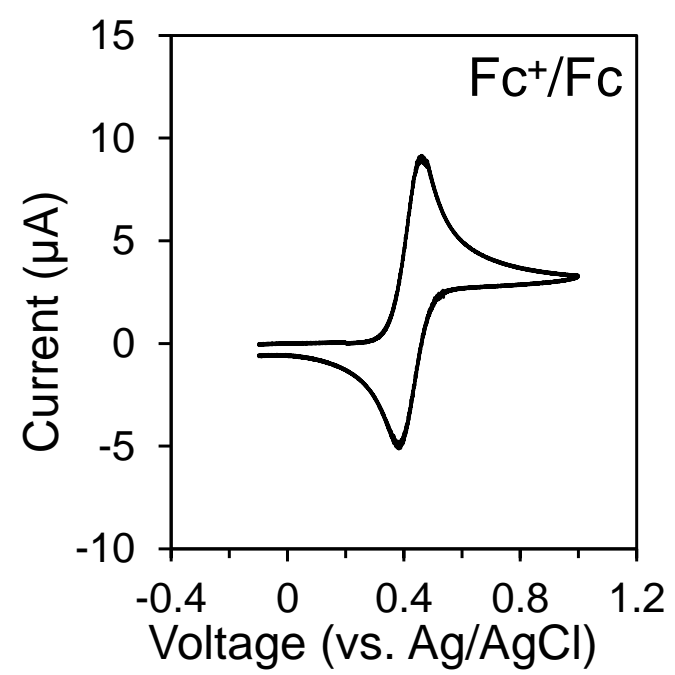

Figure S3. Calibration of the $\mathrm{Ag} / \mathrm{AgCl}$ reference electrode to ferrocenium/ferrocene redox couple. 

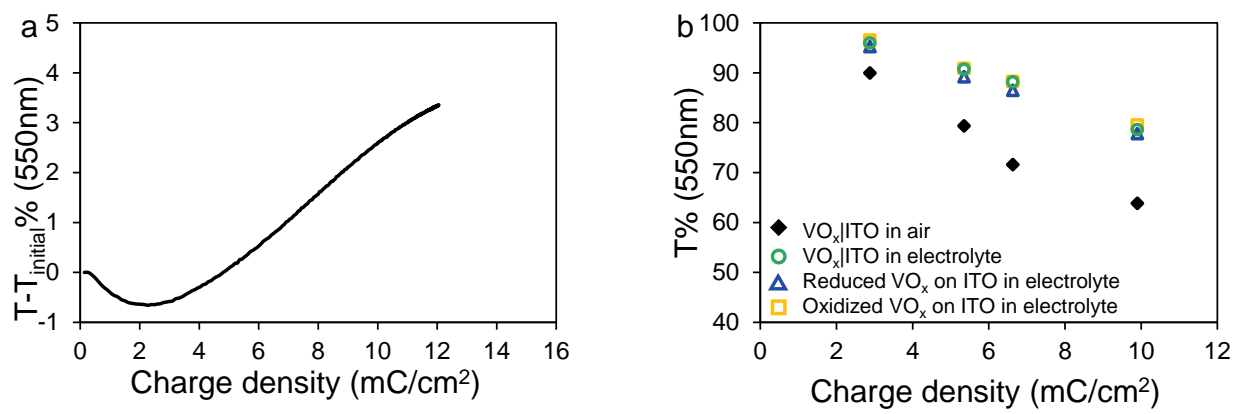

Figure S4. The relation between optical transmittance and charge density of the $\mathrm{VO}_{\mathrm{x}}$ thin films. (a) Change in transmittance at $550 \mathrm{~nm}$ as a function of increasing charge density for a $\mathrm{VO}_{\mathrm{x}}$ thin film with $\sim 80 \%$ transmittance. (b) the transmittance values of a series of $\mathrm{VO}_{\mathrm{x}}$ thin films at $550 \mathrm{~nm}$, tested in air (black, diamond), in electrolyte (green, sphere), in situ in the reduced state (blue, triangle) and in the oxidized state (yellow, square) as a function of charge density, which is measured by $\mathrm{CV}$ in the voltage range of $-0.6 \mathrm{~V}$ to $0.6 \mathrm{~V} v s$. $\mathrm{Ag} / \mathrm{AgCl}$.
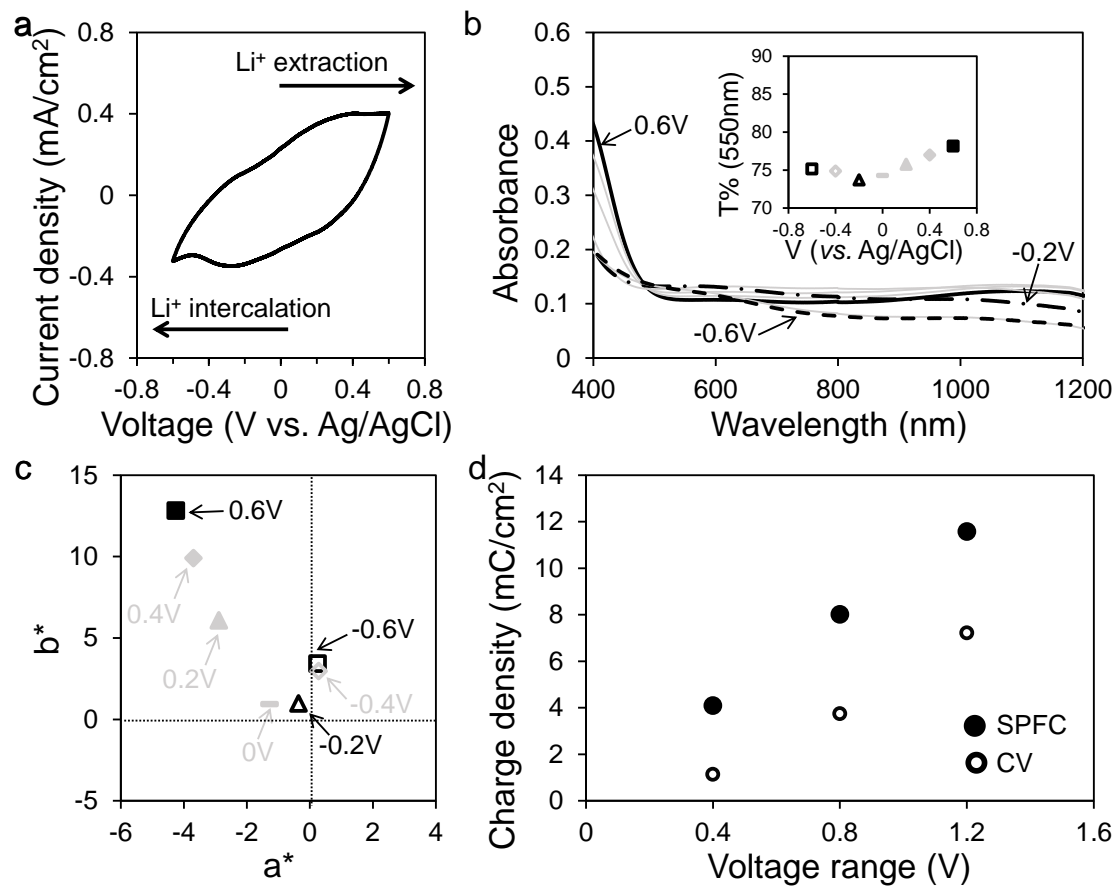

Figure S5. Electrochemical and spectroelectrochemical characterizations of the $\mathrm{VO}_{\mathrm{x}}$ thin film after 2, 500 $\mathrm{CV}$ cycles, tested in a three-electrode cell with $0.2 \mathrm{M}$ LiTFSI/PC electrolyte. (a) CV data of the $\mathrm{VO}_{\mathrm{x}}$ thin film in the voltage range of $-0.6 \mathrm{~V}$ to $0.6 \mathrm{~V}$ vs. $\mathrm{Ag} / \mathrm{AgCl}$ after cycling. (b) Absorbance of the $\mathrm{VO}_{\mathrm{x}}$ thin film at varying voltages after cycling, with transmittance values at $550 \mathrm{~nm}$ shown in the inset. (c) CIE $a^{*}$ and $b^{*}$ coordinate values of the $\mathrm{VO}_{\mathrm{x}}$ thin film at varying voltages after cycling (d) charge density as a 
function of voltage range, obtained by both $\mathrm{CV}$ (hollow) and SPFC (solid) for the $\mathrm{VO}_{\mathrm{x}}$ thin film after cycling.

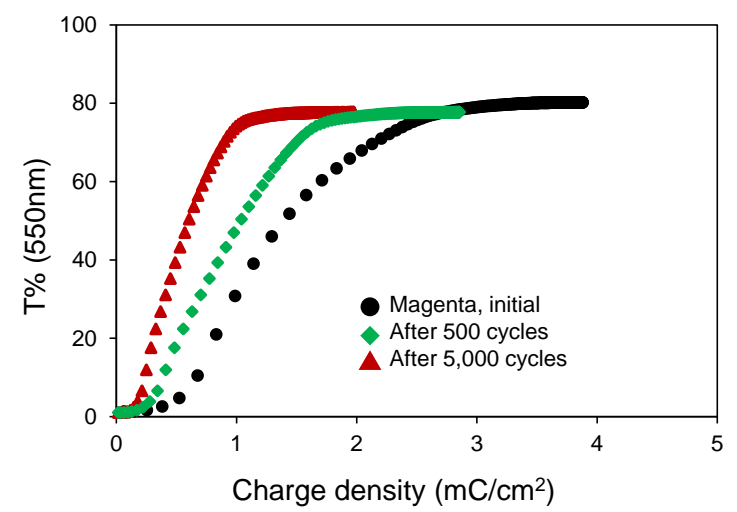

Figure S6. Change in transmittance at $550 \mathrm{~nm}$ as a function of charge density for the ECP-Magenta in the initial state (black), after 500 SPFC cycles (green) and after 5,000 SPFC cycles (red). 